\title{
Recognizing Dew as an Indicator and an Improver of Near-Surface Air Quality
}

\author{
Yingying $\mathrm{Xu}$ and Xinyue Zhu \\ Key Laboratory of Songliao Aquatic Environment, Ministry of Education, Jilin Jianzhu University, Xincheng St., Dist. 5088, \\ Changchun 130118, China \\ Correspondence should be addressed to Yingying Xu; xuyingying.1019@aliyun.com
}

Received 25 May 2017; Accepted 2 July 2017; Published 6 August 2017

Academic Editor: Harry D. Kambezidis

Copyright (C) 2017 Yingying Xu and Xinyue Zhu. This is an open access article distributed under the Creative Commons Attribution License, which permits unrestricted use, distribution, and reproduction in any medium, provided the original work is properly cited.

The relationship between dew and airborne particles is important in urban ecosystems, but the capability of dew to remove airborne particles remains unclear. During 2015 in Changchun, China, 74 dew and particle samples were collected simultaneously to investigate their chemical characteristics under normal, fog, and haze conditions. Analyses included measuring total dissolved solids, total suspended particulates, $\mathrm{PM}_{2.5}$ and $\mathrm{PM}_{10}$ concentrations, major cations $\left(\mathrm{NH}_{4}^{+}, \mathrm{Na}^{+}, \mathrm{K}^{+}, \mathrm{Ca}^{2+}\right.$, and $\left.\mathrm{Mg}^{2+}\right)$, major anions $\left(\mathrm{F}^{-}, \mathrm{Cl}^{-}, \mathrm{SO}_{4}{ }^{2-}\right.$, and $\left.\mathrm{NO}_{3}{ }^{-}\right)$, and organic and elemental carbon. Results showed that air quality deteriorated during haze but improved in fog. The particle size distributions, major cations, and carbonaceous species documented in the dew and airborne particles demonstrated consistent synchronous patterns with values descending in the order haze $>$ normal $>$ fog conditions. We found that dew is a good indicator of near-surface air quality. Specifically, its water-soluble ions and carbonaceous species could be used to distinguish emission sources and to identify the presence of secondary organic carbon. Dew is more effective at removing airborne particles in normal weather than in haze or fog conditions; $\mathrm{PM}_{2.5}$ removal rates were $21.5 \%, 15.2 \%$, and $13.7 \%$ on normal, foggy, and hazy days, respectively. Dew condensation processes reduce concentrations of gaseous and particulate pollutants in the near-surface layer.

\section{Introduction}

Dew condensation is a common meteorological phenomenon. Because of urban surface hardening and the heat island effect, not only is the frequency of dew occurrence in urban ecosystems high, but also the condensation quantity is large $[1,2]$. The dew condensation process represents effective natural atmospheric purification $[3,4]$. Airborne particles can be captured as condensation nuclei as dew condenses, whereas gases or liquid particles might dissolve into the dewdrops [5]. Thus, dew formation can actually help purify urban air [3], and dew is recognized as the sink of nighttime moisture and near-surface particulate matter (e.g., $\mathrm{PM}_{2.5}$ and $\mathrm{PM}_{10}$ ) [6]. The concentrations of both particulate matter and ions in dew are higher than in rain samples $[1,7]$. The sedimentation of airborne particles is linked to both wet deposition (rain, snow, fog, and dew) and dry sedimentation processes (gravity settling), although the former is the primary pathway via which pollutants are removed from the atmosphere [8].
Huo et al. [9] and Hu et al. [10] concluded that rain is most efficient at removing particles and gases from the atmosphere. However, the difficulties associated with dew collection have resulted in little research on near-surface airborne particle removal by dew [11]. Dew condensation is concentrated within the layer $0-3 \mathrm{~m}$ above the ground surface $[6,12]$. Near-surface airborne particulate matter, particularly $\mathrm{PM}_{2.5}$ and $\mathrm{PM}_{10}$, has direct and strong influence on human health [13]. However, although dew is an important pathway of wet deposition in the sphere of human activity, it remains unclear how much atmospheric particulate matter might be removed by dew.

Following China's rapid urbanization, motor vehicle exhaust emissions, industrial waste gases, and coal combustion have created increasing levels of urban air pollution [14]. The associated higher concentrations of particulate matter, which lead to increased occurrences of foggy and hazy weather under conditions of high relative humidity $(\mathrm{RH})$ and temperature inversion, have become problematic [15-17]. 
On hazy days, the concentrations of water-soluble ions in dew have been found to be 3.01-9.32 times higher than on normal days. The mean concentrations of $\mathrm{PM}_{2.5}$ and $\mathrm{PM}_{10}$ have been reported as 21.69 and $51.56 \mathrm{mg} / \mathrm{L}$, respectively, on normal days, that is, over 2.48 and 1.79 times higher than on hazy days, respectively [18]. Thus, water vapor condensation is clearly involved in the settling of airborne particles [19], making dew condensation an effective method of their sedimentation and removal. However, a relationship between dew and airborne particle concentrations, that is, one that reflects the chemical transformation of atmospheric pollutants in condensation processes under various conditions, has yet to be established. The objectives of this study were to analyze the chemical characteristics of dew and airborne particles under normal, foggy, and hazy conditions; to discuss the relationship between particles and dew; and to identify the particle removal capability of dew under different weather conditions. The intentions were to identify changes in the chemical compositions of the dew and the airborne particles under these various conditions and to reveal the contribution of dew to the removal of near-surface airborne particles.

\section{Materials and Methods}

2.1. Sampling Site. Dew and airborne particle samples were collected at Jilin Jianzhu University, located in the southeastern part of Changchun in Jilin Province, China. The continental monsoon climate of the area produces average annual temperatures that vary from $-15^{\circ} \mathrm{C}$ in January to $25^{\circ} \mathrm{C}$ in August. Precipitation that falls mostly as rain is within the range of $522-615 \mathrm{~mm} / \mathrm{a}$. Changchun has four distinct seasons that are characterized by freezing weather in winter, relatively strong winds in spring, and high $\mathrm{RH}$, an obvious diurnal temperature difference, and low wind speed $(<2 \mathrm{~m} / \mathrm{s})$ in summer and fall. The synergistic atmospheric conditions of a seasonal temperature inversion and airborne pollutants caused by the burning of corn, straw, or fossil fuels mean Changchun historically suffers hazy conditions in autumn. To investigate the nature of this haze, samples of dew and aerosols were collected during the peak haze period of summer and fall (May-November) in 2015.

\subsection{Sample Collection}

2.2.1. Dew. Dew samples collected using different collection surfaces can vary substantially [11]; however, a polytetrafluoroethylene (PTFE) surface is generally considered appropriate for dew collection [20]. In this study, dew was collected in clean $250 \mathrm{~mL}$ PTFE bottles placed (approximately $1.0 \mathrm{~m}$ above ground level) within the green belt along a campus road. This site is affected by residential, traffic, and construction emissions considered representative of Changchun. All dew samples were collected before sunrise on nonrainy days to avoid any effects on particle concentrations associated with rain.

2.2.2. Airborne Particles. Airborne particle samples were collected simultaneously with the dew samples. Thus, the sampling time was equivalent to the dew condensation period, that is, between 18:00 and 06:00 local time. Samples were collected at approximately $1.0 \mathrm{~m}$ above ground level, next to the dew collector. Particles were collected onto Whatman quartz filters (QMA 1851-047), using medium-volume samplers and a flow rate of $100 \mathrm{~L} / \mathrm{min}$. After sampling, the filters were placed into polyethylene plastic bags and stored in a refrigerator.

\subsection{Sample Analysis}

2.3.1. Ion Analysis. All dew water samples were filtered through $0.45 \mu \mathrm{m}$ membrane filters and stored at approximately $4^{\circ} \mathrm{C}$ for further chemical analysis. Major soluble cations $\left(\mathrm{Ca}^{2+}, \mathrm{Mg}^{2+}\right.$, $\mathrm{Na}^{+}, \mathrm{K}^{+}$, and $\left.\mathrm{NH}_{4}{ }^{+}\right)$and anions $\left(\mathrm{F}^{-}, \mathrm{Cl}^{-}, \mathrm{NO}_{3}{ }^{-}\right.$, and $\mathrm{SO}_{4}{ }^{2-}$ ) were analyzed using an ion chromatograph (LC-20AD, Shimadzu, Japan). Specifically, a Shim-pack IC-C1 column, with $5 \mathrm{mmol} \mathrm{HNO}_{3}$ as eluent and a $1.3 \mathrm{~mL} / \mathrm{min}$ flow rate, was used to analyze $20 \mu \mathrm{L}$ of each sample for cations. Similarly, a Shimpack IC-A3 column, with $8.0 \mathrm{mmol} p$-hydroxybenzoic acid (PHBA), $3.2 \mathrm{mmol}$ Bis-Tris, and $50 \mathrm{mmol}$ boric acid as eluent and a $1.5 \mathrm{~mL} / \mathrm{min}$ flow rate, was used to analyze $50 \mu \mathrm{L}$ of each sample for anions [18].

Airborne particles collected on the filters were submerged in $20 \mathrm{~mL}$ of ultrapure water, sealed, and ultrasonicated for approximately $120 \mathrm{~min}$ to extract soluble ions. Subsequently, the same steps as described above for dew samples were undertaken to determine the soluble ion content.

2.3.2. Carbonaceous Species. The total carbon (TC) and elemental carbon (EC) quantities on each quartz filter were determined using an elemental analyzer (EA-1108 CHNS-O, Fisons, Italy). One-eighth of each filter sample was preheated at $340^{\circ} \mathrm{C}$ for $100 \mathrm{~min}$ to expel the organic carbon (OC) content; this subsample was fed into the elemental analyzer to obtain the EC content. The OC was determined by extracting the EC from the TC content.

Particulate organic carbon (POC) and particulate elemental carbon (PEC) in all the dew samples were filtered through $0.45 \mu \mathrm{m}$ membrane filters to remove any particulate matter. This residue was then weighed after having been freeze-dried for $12 \mathrm{~h}$. All subsequent steps were identical to the process described above for aerosol samples. The POC was determined by extracting the PEC from the particle total carbon (PTC) content.

2.3.3. Particle Diameter Analysis. Particle diameters in dew were measured using a model JL-1166 Laser Particle Analyzer (JL-1166, Chengdu Jingxin Powder Analysis Instrument Co., Ltd., Chengdu, Sichuan, China).

Particle diameters in dew were measured using an Aerosol Monitors Model (DUSTTRAK ${ }^{\mathrm{TM}}$ DRX 8533EP, USA).

2.3.4. TDS, TSP, and PM Measurements. Data of total suspended particulate (TSP), $\mathrm{PM}_{2.5}$ (particulate matter diameter $<2.5 \mu \mathrm{m}$ ), and $\mathrm{PM}_{10}$ (particulate matter diameter 2.5-10 $\mu \mathrm{m}$ ) in Changchun were collated from http://www.pm25.in/ changchun.

All collected dew samples were analyzed to determine the total dissolved solids (TDS), $\mathrm{PM}_{2.5}$, and $\mathrm{PM}_{10}$ using the 
TABLE 1: Average meteorological parameters and particle concentrations during normal, fog, and haze conditions during the study period.

\begin{tabular}{lccc}
\hline & Normal & Fog & Haze \\
\hline AQI & 87 & 71 & 272 \\
$\mathrm{PM}_{2.5}\left(\mu \mathrm{g} / \mathrm{m}^{3}\right)$ & 32 & 33 & 230 \\
$\mathrm{PM}_{10}\left(\mu \mathrm{g} / \mathrm{m}^{3}\right)$ & 68 & 52 & 292 \\
$\mathrm{RH}(\%)$ & 75.27 & 92.12 & 81.25 \\
Wind speed $(\mathrm{m} / \mathrm{s})$ & 0.66 & 0.12 & 0.24 \\
Visibility $(\mathrm{km})$ & 12.48 & 5.36 & 3.58 \\
Pressure $(\mathrm{kPa})$ & 101.5 & 101.3 & 101.1 \\
Dew point $\left({ }^{\circ} \mathrm{C}\right)$ & 19.0 & 18.5 & 4.1 \\
Temperature $\left({ }^{\circ} \mathrm{C}\right)$ & 17.52 & 15.26 & 6.28 \\
\hline
\end{tabular}

Note. AQI: Air Quality Index; $\mathrm{PM}_{2.5}$ : particulate matter $<2.5 \mu \mathrm{m}$ in diameter; $\mathrm{PM}_{10}$ : particulate matter $2.5-10 \mu \mathrm{m}$ in diameter.

subtraction method. The samples filtered through 10.00, 2.50, or $0.22 \mu \mathrm{m}$ membrane filters were weighed and then dried for $12 \mathrm{~h}$. After drying, the filters were reweighed and the TDS, $\mathrm{PM}_{2.5}$, and $\mathrm{PM}_{10}$ of the dew were calculated based on their differences.

2.4. Dew Intensity Monitoring. Dew is difficult to create artificially; therefore, the experiments were conducted in situ. Poplar wooden sticks were chosen as the monitoring material. The poplar wooden sticks were polished and cut to a size of $20 \times 4 \times 4 \mathrm{~cm}$ (length $\times$ width $\times$ height).

An observation shelf was set up with three layers: a lower layer ( $5 \mathrm{~cm}$ above the ground surface), a middle layer $(1.5 \mathrm{~m}$ above the ground surface), and an upper layer ( $3 \mathrm{~m}$ above the ground surface). The middle and upper monitors mainly estimated the dew formed by condensation of atmospheric water vapor, and the lower monitor mainly estimated dew formed from water vapor rising from the surface of the ground. The monitors were weighed daily at sunset and sunrise with an electronic balance (accuracy: $\pm 0.001 \mathrm{~g}$ ). For each height, three monitors were set up $30 \mathrm{~min}$ after sunset. These monitors were gathered $30 \mathrm{~min}$ before sunrise and reweighed. The actual dew per unit area for each plot was computed as the average of the three heights. The monitors were left in the experiment plot during the day to prevent excessive drying and to eliminate the effects of moisture absorption on measurement accuracy.

2.5. Data Analysis. Statistical analyses were conducted using SPSS software version 16.0 (IBM Corp., NY, USA). QuantileQuantile Probability Plots were used to test the normality of the meteorological data, particle removal efficiency by dew, and particle concentrations in dew and air on foggy, normal, and hazy days. Values all accorded with a normal distribution, and the average data could be used to describe the results of the analysis. Wind speed, $\mathrm{RH}, \mathrm{PM}_{25}$, and $\mathrm{PM}_{10}$ data were subjected to a one-way analysis of variance with a significance threshold of $p<0.05$. Either the Least Significance Difference method or Tamhane's T2 procedure was used to determine the differences among the meteorological data. follows:

The equations of particle removal efficiency by dew are as

$$
R_{i} \%=\frac{Q_{i \mathrm{dew}}}{Q_{i \mathrm{air}}} \times 100 \%,
$$

where $i$ is the type of PM $\left(i=1\right.$ represents $\mathrm{PM}_{2.5}, i=2$ represents $\mathrm{PM}_{10}$, and $i=3$ represents TSP), $R$ is the particle removal efficiency by dew, $Q_{i \text { dew }}$ is the weight of particles after sunset in the dew (mg), and $Q_{i \text { air }}$ is the weight of particles in the air during the condensation time (mg);

$$
Q_{i \mathrm{dew}}=I \times C_{i} \times \frac{V}{3},
$$

where $I$ is the dew intensity $(\mathrm{mm}), C_{i}$ is the concentration of particles in the dew $(\mathrm{mg} / \mathrm{L}), V$ is the air inflow during dew condensation $\left(\mathrm{m}^{3}\right)$, and 3 is the hypothetical dew condensation concentrated $0-3 \mathrm{~m}$ above the ground surface;

$$
I=\frac{10 \times\left(W_{m r}-W_{m s}\right)}{S},
$$

where $W_{m r}$ is the weight of each monitor in the different layers before sunrise $(\mathrm{g}), W_{m s}$ is the weight of each monitor in the different layers after sunset $(\mathrm{g}), S$ is the surface area of the monitor $\left(\mathrm{cm}^{2}\right)$, and 10 is a conversion factor;

$$
Q_{i \text { air }}=W_{f i r}-W_{f i s},
$$

where $W_{f i r}$ is the weight of the filter before sunrise (g) and $W_{f i s}$ is the weight of the filter after sunset (g).

2.6. Classification of Normal, Foggy, and Hazy Conditions. Normal, foggy, and hazy weather were defined based on the $\mathrm{RH}$ and visibility during the study period. Normal days had visibility of $>10 \mathrm{~km}$. Hazy days had visibility of $<10 \mathrm{~km}$ and RH of $<90 \%$. Foggy days had visibility of $<10 \mathrm{~km}$ but with $\mathrm{RH}$ of $>90 \%$. Using these criteria, airborne particles and dew samples were collected on 17 normal, 13 hazy, and 7 foggy days.

The meteorological parameters for these three weather conditions are shown in Table 1 . Haze and fog were characterized by low visibility and a high Air Quality Index (AQI). 
TABLE 2: Summary of removal efficiency (\%) of total dissolved solids (TDS), $\mathrm{PM}_{2.5}$, and $\mathrm{PM}_{10}$ by dew in Changchun during the study period.

\begin{tabular}{lccccccccc}
\hline & \multicolumn{3}{c}{ Normal $(n=17)$} & \multicolumn{3}{c}{ Fog $(n=7)$} & \multicolumn{3}{c}{ Haze $(n=13)$} \\
& TDS & $\mathrm{PM}_{2.5}$ & $\mathrm{PM}_{10}$ & TDS & $\mathrm{PM}_{2.5}$ & $\mathrm{PM}_{10}$ & $\mathrm{TDS}_{2.5}$ & $\mathrm{PM}_{10}$ \\
\hline Mean \pm SD & $28.2 \pm 3.6$ & $21.5 \pm 3.8$ & $25.9 \pm 2.5$ & $23.7 \pm 3.1$ & $15.2 \pm 3.5$ & $18.1 \pm 4.1$ & $18.5 \pm 3.9$ & $13.7 \pm 1.1$ & $15.7 \pm 1.2$ \\
Max. & 32.3 & 25.9 & 28.5 & 27.4 & 19.5 & 25.4 & 24.1 & 14.5 & 18.4 \\
Min. & 17.5 & 18.7 & 19.5 & 18.4 & 10.5 & 14.1 & 15.2 & 11.8 & 12.7 \\
\hline
\end{tabular}

Fog had high humidity and low wind speed, while haze was associated with stable moist air. Aside from the $\mathrm{RH}$ and visibility, the main meteorological parameter that differed between foggy and normal weather was wind speed $(p<$ $0.01)$, while temperature $(p<0.01)$ distinguished hazy and normal days. The burning of coal and straw for heating is the principal cause of haze in Changchun. Therefore, haze usually occurs in fall or winter under low temperature conditions. This results in concentrations of $\mathrm{PM}_{2.5}$ and $\mathrm{PM}_{10}$ in haze that are significantly higher than on normal days $(p<0.01)$.

2.7. Meteorological Data. Daily meteorological data, including air temperature $\left({ }^{\circ} \mathrm{C}\right)$, dew point $\left({ }^{\circ} \mathrm{C}\right), \mathrm{RH}(\%)$, wind speed $(\mathrm{m} / \mathrm{s})$ at $10 \mathrm{~m}$ height, and water vapor pressure $(\mathrm{hPa})$, were measured at hourly intervals during the condensation period using a Milos 520 automatic weather station (Vaisala, Finland) at Jilin University. Visibility data were collated from http://www.wunderground.com. Data for $\mathrm{PM}_{2.5}$ and $\mathrm{PM}_{10}$ in Changchun were collated from http://www.pm25.in/changchun.

\section{Results and Discussion}

3.1. Particulate Matter. Under normal conditions, in this study, most airborne particles comprised $\mathrm{PM}_{20}-\mathrm{PM}_{50}$ (diameter: $20-50 \mu \mathrm{m}$ ), accounting for $28.32 \%$ of the total particulate mass (Figure 1). Meanwhile, the proportions of $\mathrm{PM}_{2.5}$, $\mathrm{PM}_{10}$, and $>\mathrm{PM}_{10}$ were $11.83 \%, 25.69 \%$, and $62.48 \%$, respectively. Thus, coarse particles $>\mathrm{PM}_{10}$ formed the dominant fraction of the particulate matter. In fog, the particle size distributions changed little with proportions of $\mathrm{PM}_{2.5}, \mathrm{PM}_{10}$, and $>\mathrm{PM}_{10}$ established as $12.78 \%, 27.23 \%$, and $59.99 \%$, respectively. Because fog usually occurred after rainfall, air quality on such days was generally good. Thus, the coarse particle fraction $\mathrm{PM}_{20}-\mathrm{PM}_{50}$ declined under fog from normal levels $(28.32 \%)$ to $18.58 \%$. Air pollution is most serious during haze because of the much higher concentrations of fine particulate matter. In haze, the proportions of $\mathrm{PM}_{2.5}$ and $\mathrm{PM}_{10}$ increased from normal levels to $19.35 \%$ and $31.10 \%$, respectively, while the proportion of $>\mathrm{PM}_{10}$ declined to $49.55 \%$.

Because airborne particles near the surface act as condensation nuclei for dew, the particle size distributions for both dew and airborne particles were concordant (Figure 1). Under normal weather conditions, dew preferentially removed coarse airborne particles, resulting in a proportion of $>\mathrm{PM}_{10}$ of $67.14 \%$. Particle size distributions in dew associated with foggy and normal weather were identical; however, during hazy weather, the fine particulate fraction in dew was clearly
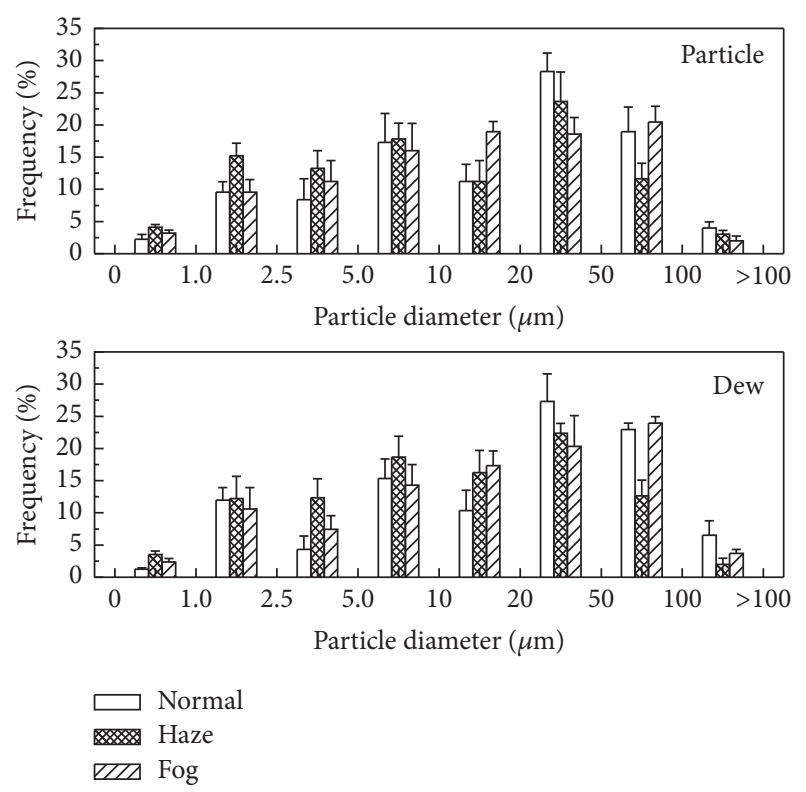

FIGURE 1: Frequency size distributions of air particles and dew in normal, hazy, and foggy conditions in Changchun, China.

enhanced, increasing from $32.86 \%$ under normal weather conditions to $46.78 \%$ in haze. Removal of coarse airborne particles by dew is clearly a dominant process under normal, foggy, and hazy weather (Table 2).

As shown in Table 3, the mass concentrations of TSP, $\mathrm{PM}_{2.5}$, and $\mathrm{PM}_{10}$ in the atmosphere were 165.24, 40.22, and $72.34 \mu \mathrm{g} / \mathrm{m}^{3}$ on normal days. In contrast, the mass concentrations of TSP, $\mathrm{PM}_{2.5}$, and $\mathrm{PM}_{10}$ deceased 0.66-0.75 times in fog. Such decreases reflect the better air quality under fog conditions. In contrast, a reduction in air quality was obvious in hazy weather with mass concentrations of TSP, $\mathrm{PM}_{2.5}$, and $\mathrm{PM}_{10}$ having values 2.78-4.29 times those of normal weather. Mean concentrations of TDS, $\mathrm{PM}_{2.5}$, and $\mathrm{PM}_{10}$ in dew were all higher in haze compared with normal days, reflecting the higher total dissolved ions in dew produced on hazy days. Table 2 shows that dew can effectively remove airborne particles. In normal weather, the removal rates of TSP, $\mathrm{PM}_{10}$, and $\mathrm{PM}_{2.5}$ by dew were $28.2 \%, 25.9 \%$, and $21.5 \%$, respectively. In foggy and hazy weather, the capability of dew to remove airborne particles decreased significantly, especially in haze. The removal rates of TSP, $\mathrm{PM}_{10}$, and $\mathrm{PM}_{2.5}$ by dew decreased to $18.5 \%, 15.7 \%$, and $13.7 \%$ under haze. Hazy and foggy weather limit the airborne particle removal capability of dew condensation. 


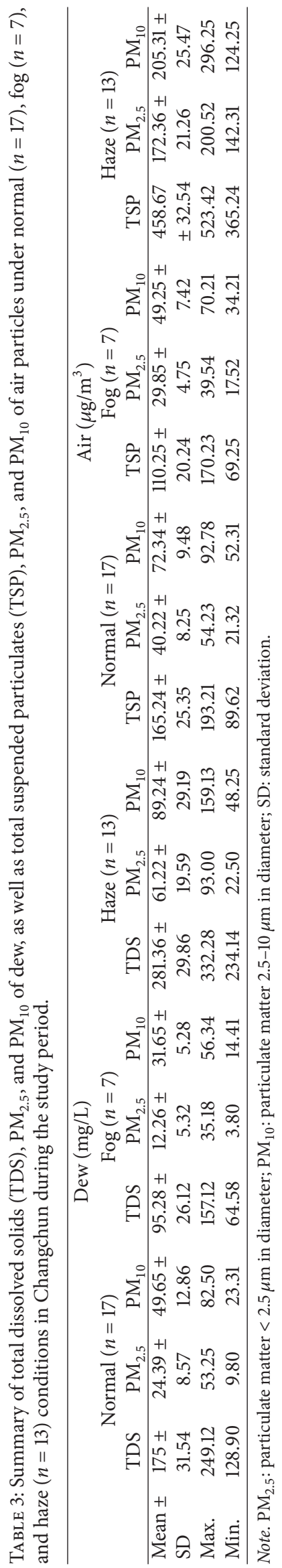



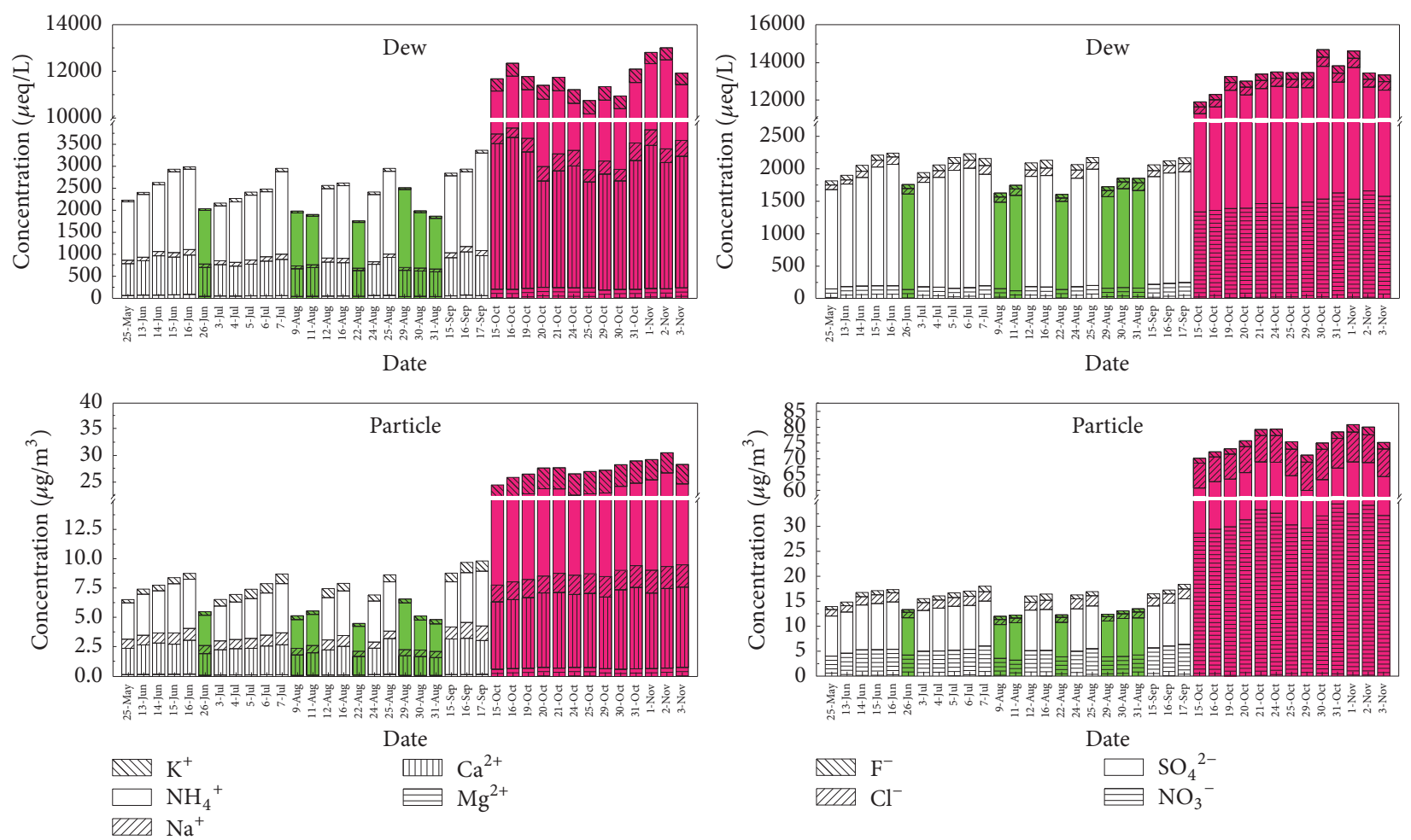

FIGURE 2: Ionic concentrations of $\mathrm{NH}_{4}^{+}, \mathrm{Mg}^{2+}, \mathrm{Ca}^{2+}, \mathrm{K}^{+}, \mathrm{Na}^{+}, \mathrm{Cl}^{-}, \mathrm{NO}_{3}{ }^{-}, \mathrm{F}^{-}$, and $\mathrm{SO}_{4}{ }^{2-}$ of air particles and dew under normal (white), foggy (green), and hazy (red) conditions in Changchun, China.

Particle concentrations in dew were similar to those in the atmosphere under all conditions. Mass concentrations of TDS, $\mathrm{PM}_{2.5}$, and $\mathrm{PM}_{10}$ in dew were 175.31, 24.39, and $49.65 \mathrm{mg} / \mathrm{L}$ on normal days. Their values declined $0.50-0.63$ times in fog but increased 1.60-2.54 times in haze. Therefore, the capability of dew to remove particulate matter appears to be diminished under fog and haze. This might reflect the more static meteorological conditions during fog and haze events, in which floating particles do not settle easily. Only a fraction of near-surface atmospheric particulate matter appeared to act as condensation nuclei, adsorbing water vapor. Under normal weather conditions, particles removed by dew include condensation nuclei and any airborne particles that would naturally undergo sedimentation.

3.2. Ionic Composition. Air quality obviously decreases during haze. Mass concentrations of $\mathrm{PM}_{2.5}$ and $\mathrm{PM}_{10}$ are typically 4-6 times higher during haze than on normal days [21] with almost all concentrations of water-soluble ions $\left(\mathrm{NH}_{4}{ }^{+}, \mathrm{Mg}^{2+}\right.$, $\mathrm{Ca}^{2+}, \mathrm{K}^{+}, \mathrm{Na}^{+}, \mathrm{Cl}^{-}, \mathrm{NO}_{3}{ }^{-}, \mathrm{F}^{-}$, and $\mathrm{SO}_{4}{ }^{2-}$ ) showing increases during haze events $[22,23]$. In particular, the concentrations of $\mathrm{K}^{+}$and other secondary aerosol indicators $\left(\mathrm{NH}_{4}{ }^{+}, \mathrm{NO}_{3}{ }^{-}\right.$, and $\mathrm{SO}_{4}{ }^{2-}$ ) increase markedly in haze $[21,23]$. This study focused on air quality during haze events (Table 1), when haze formed more than $10 \mathrm{~m}$ above ground level $[21,24,25]$. We found that ion concentrations in both dew and particulate matter of the atmosphere were similar (Figure 2). In decreasing order of ionic concentration, airborne particles comprised $\mathrm{SO}_{4}{ }^{2-}>\mathrm{NO}_{3}{ }^{-}>\mathrm{NH}_{4}{ }^{+}>\mathrm{Ca}^{2+}>\mathrm{Cl}^{-}>\mathrm{Na}^{+}>\mathrm{F}^{-}>$
$\mathrm{K}^{+}>\mathrm{Mg}^{2}$. Although ion concentrations in fog were reduced, this order did not change. In contrast, during haze, ion concentrations increased and the decreasing order of ionic concentrations in airborne particles changed to $\mathrm{SO}_{4}{ }^{2-}>\mathrm{NO}_{3}{ }^{-}>$ $\mathrm{NH}_{4}{ }^{+}>\mathrm{Cl}^{-}>\mathrm{Ca}^{2+}>\mathrm{K}^{+}>\mathrm{F}^{-}>\mathrm{Na}^{+}>\mathrm{Mg}^{2+}$. Ions from anthropogenic pollution sources were the highest contributors to airborne particles in normal, foggy, and hazy weather. In particular, $\mathrm{Cl}^{-}$from coal and $\mathrm{K}^{+}$from biomass burning were most enhanced in haze events. In dew, the decreasing order of ionic concentrations under normal and foggy conditions was $\mathrm{SO}_{4}{ }^{2-}>\mathrm{NH}_{4}{ }^{+}>\mathrm{Ca}^{2+}>\mathrm{NO}_{3}{ }^{-}>\mathrm{Cl}^{-}>\mathrm{Na}^{+}>$ $\mathrm{F}^{-}>\mathrm{K}^{+}>\mathrm{Mg}^{2+}$. In addition to the finding that all ion concentrations in dew during hazy weather were enhanced considerably, their order was also changed to $\mathrm{SO}_{4}{ }^{2-}>\mathrm{NH}_{4}{ }^{+}>$ $\mathrm{Ca}^{2+}>\mathrm{NO}_{3}{ }^{-}>\mathrm{K}^{+}>\mathrm{Cl}^{-}>\mathrm{F}^{-}>\mathrm{Na}^{+}>\mathrm{Mg}^{2+}$.

At the study site, ammonia $\left(\mathrm{NH}_{3}\right)$ constituted an important alkaline gas in the atmosphere. The secondary aerosol was $\mathrm{NO}_{3}{ }^{-}$, which results from the transformations of various precursors of $\mathrm{NO}_{x}$ [22]. The concentration of $\mathrm{NH}_{4}^{+}$was higher than $\mathrm{NO}_{3}{ }^{-}$in dew but not in airborne particles. Furthermore, $\mathrm{NH}_{4}{ }^{+}$showed strong correlations with $\mathrm{SO}_{4}{ }^{2-}$ and $\left[\mathrm{SO}_{4}{ }^{2-}+\mathrm{NO}_{3}{ }^{-}\right](p<0.01)$ in both dew and particle samples. The slopes of the regression equations between $\mathrm{NH}_{4}{ }^{+}$and $\left[\mathrm{SO}_{4}{ }^{2-}+\mathrm{NO}_{3}{ }^{-}\right]$and $\mathrm{NH}_{4}{ }^{+}$and $\mathrm{SO}_{4}{ }^{2-}$ in dew were both smaller than unity (0.76 and 0.85$)$, indicating incomplete neutralization of acidic species $\left(\mathrm{HNO}_{3}\right.$ and $\mathrm{H}_{2} \mathrm{SO}_{4}$ ) by ammonia during the study period. This suggests the dominance of $\left(\mathrm{NH}_{4}\right)_{2} \mathrm{SO}_{4}$ and $\mathrm{NH}_{4} \mathrm{HSO}_{4}$ [26] in the 
urban atmosphere. Thus, excess ammonia could combine with chloride and oxalate to form $\mathrm{NH}_{4} \mathrm{Cl}$ and $\left(\mathrm{NH}_{4}\right)_{2} \mathrm{CO}_{3}$. Diurnal variability was observed for gaseous $\mathrm{NH}_{3}$ in the surface layer, and its concentration was higher than $\mathrm{NO}_{2}$ during periods of dew condensation [27]. Meanwhile, the concentration of $\mathrm{HNO}_{3}$ was higher during daytime [28]. This suggests that $\mathrm{NH}_{3}$ is readily converted to $\mathrm{NH}_{4}{ }^{+}$in dew at night. Otherwise, it is possible that $\mathrm{NH}_{3}$ is dissolved easily in an acidic environment, whereby acidic dew accelerates the conversion of $\mathrm{NH}_{3}$ to $\mathrm{NH}_{4}{ }^{+}$[29]. These scenarios all result in higher $\mathrm{NH}_{3}$ concentrations in dew.

All ionic species in both airborne particles and dew decreased in transitions from normal to foggy conditions, but they increased in transitions from normal to hazy conditions. The origins of $\mathrm{Ca}^{2+}, \mathrm{Na}^{+}$, and $\mathrm{Mg}^{2+}$ are mainly from crustal sources such as resuspended road dust, soil dust, and construction dust, while $\mathrm{SO}_{4}{ }^{2-}, \mathrm{NO}_{3}{ }^{-}$, and $\mathrm{NH}_{4}{ }^{+}$ represent secondary pollution sources. Usually, $\mathrm{F}^{-}$and $\mathrm{Cl}^{-}$ are derived from coal combustion, while $\mathrm{K}^{+}$is derived from biomass burning. The concentration ratios for normal/foggy conditions in airborne particles and dew for the main cations and anions were 1.40 and 1.30 for $\mathrm{NH}_{4}{ }^{+}, 1.50$ and 1.32 for $\mathrm{Ca}^{2+}$, 1.60 and 1.44 for $\mathrm{Na}^{+}, 2.04$ and 1.53 for $\mathrm{K}^{+}, 1.82$ and 1.49 for $\mathrm{Mg}^{2+}, 1.19$ and 1.18 for $\mathrm{SO}_{4}{ }^{2-}, 1.37$ and 1.28 for $\mathrm{NO}_{3}{ }^{-}, 1.69$ and 1.13 for $\mathrm{Cl}^{-}$, and 1.57 and 1.47 for $\mathrm{F}^{-}$.

The effect of haze on ions from different sources in both airborne particles and dew was significantly different. Haze concentrations of crustal ions $\left(\mathrm{Ca}^{2+}, \mathrm{Na}^{+}\right.$, and $\left.\mathrm{Mg}^{2+}\right)$ in airborne particles were 1.87-5.05 times the normal particle levels; however, in dew, they were 3.26-3.69 times the normal dew levels. Haze concentrations of anthropogenic pollution species $\left(\mathrm{SO}_{4}{ }^{2-}, \mathrm{NO}_{3}{ }^{-}\right.$, and $\left.\mathrm{NH}_{4}{ }^{+}\right)$were 3.89-5.98 times the normal particle levels and 4.78-7.99 times the normal dew levels. Haze concentrations of indicator ions $\left(\mathrm{F}^{-}, \mathrm{Cl}^{-}\right.$, and $\mathrm{K}^{+}$) of coal and biomass burning were 2.27-6.05 times the normal particle levels and 3.93-8.96 times the normal dew levels. Throughout the sampling period, $\mathrm{K}^{+}$showed the largest variation in airborne particles or dew. Haze caused serious air pollution. Clearly, this pollution was attributable to species from pollution and biomass burning sources. The chemical composition of the dew closely reflected the air quality of the near-surface atmosphere. Our results suggest that analyzing the chemical characteristics of dew can provide a reference for the assessment of air pollution and air quality. In particular, water-soluble ions from different sources were enhanced in dew compared with airborne particles collected simultaneously. We also observed that, under conditions of deteriorating air quality, the capability of dew to remove airborne pollutants increased.

Dew condensation clearly had a purification effect on the near-surface atmosphere. In the process of vapor condensation, some airborne particles acted as dew condensation nuclei, while acidic or alkaline gas and solid particles dissolved directly in the dew. For instance, $\mathrm{SO}_{3}{ }^{-}$and $\mathrm{HSO}_{3}{ }^{2-}$ were partially oxidized to $\mathrm{SO}_{4}{ }^{2-}$ on oxidant surfaces, yielding the transformation of $\mathrm{SO}_{2}$ gas to $\mathrm{SO}_{4}{ }^{2-}$ solid, as outlined below in the following reactions:

$$
\begin{gathered}
\mathrm{O}_{2}(\mathrm{a})+\mathrm{SO}_{2}(\mathrm{~g}) \longrightarrow \mathrm{SO}_{3}{ }^{2-}(\mathrm{a}), \\
\mathrm{OH}^{-}(\mathrm{a})+\mathrm{SO}_{2}(\mathrm{~g}) \longrightarrow \mathrm{HSO}_{3}{ }^{2-} \text { (a) } / 2 \mathrm{OH}^{-}(\mathrm{a})+\mathrm{SO}_{2}(\mathrm{~g}) \longrightarrow \mathrm{SO}_{4}{ }^{2-}(\mathrm{a})+\mathrm{H}_{2} \mathrm{O},
\end{gathered}
$$

where (a) and (g) represent aerosol and gas phases, respectively.

Additionally, $\mathrm{SO}_{2}$ can also be absorbed by water in a liquid-phase reaction:

$$
\begin{aligned}
\mathrm{SO}_{2}+\mathrm{H}_{2} \mathrm{O} & \mathrm{SO}_{2} \cdot \mathrm{H}_{2} \mathrm{O}, \\
\mathrm{SO}_{2} \cdot \mathrm{H}_{2} \mathrm{O} & \longleftrightarrow H^{+}+\mathrm{HSO}_{3}{ }^{-}, \\
\mathrm{HSO}_{3}{ }^{-} & \longleftrightarrow \mathrm{H}^{+}+\mathrm{SO}_{3}{ }^{2-},
\end{aligned}
$$

where italics are used to show ionic species.

Thus, $\mathrm{SO}_{4}{ }^{2-}$ in dew could originate from either homogeneous or heterogeneous chemical transformations of $\mathrm{SO}_{2}$ and $\mathrm{SO}_{4}{ }^{2-}$. We suggest that part of the $\mathrm{SO}_{4}{ }^{2-}$ fraction might come from particles formed from gas or from gas absorption on particle surfaces. Clearly, conversion of $\mathrm{SO}_{2}$ to $\mathrm{SO}_{4}{ }^{2-}$ was accelerated by dew condensation. We conclude that condensation processes reduce pollutant concentrations of both gases and particulates in the near-surface atmosphere.
3.3. Carbonaceous Species. During this study, the concentrations of carbonaceous species showed similar trends to water-soluble species with the greatest levels in descending order recorded in hazy $>$ normal $>$ foggy conditions. The concentrations of OC and EC in airborne particles and the POC and PEC in dew were the highest in haze and the lowest in fog (Figure 3). The average daily concentrations in airborne particles from hazy, foggy, and normal conditions were $40.75,10.10$, and $14.52 \mu \mathrm{g} / \mathrm{m}^{3}$ for OC and $7.91,2.82$, and $3.84 \mu \mathrm{g} / \mathrm{m}^{3}$ for EC, respectively. These values were 70.96 , 7.38 , and $10.85 \mathrm{mg} / \mathrm{L}$ for POC and $13.43,2.73$, and $3.51 \mathrm{mg} / \mathrm{L}$ for PEC in dew, under hazy, foggy, and normal conditions, respectively.

A ratio of $\mathrm{OC} / \mathrm{EC}>2$ was used to identify the presence of secondary organic carbon (SOC) [21]. The average OC/EC ratio (5.16) in haze was about 1.43 times higher than in fog (3.60) and 1.35 times higher than on normal weather days (3.80). These ratios show that SOC formation was most serious during haze. In this study, average OC/EC ratios were 3.10, 2.72, and 5.33 for normal, foggy, and hazy conditions, respectively. The changes in OC and EC in dew and airborne 


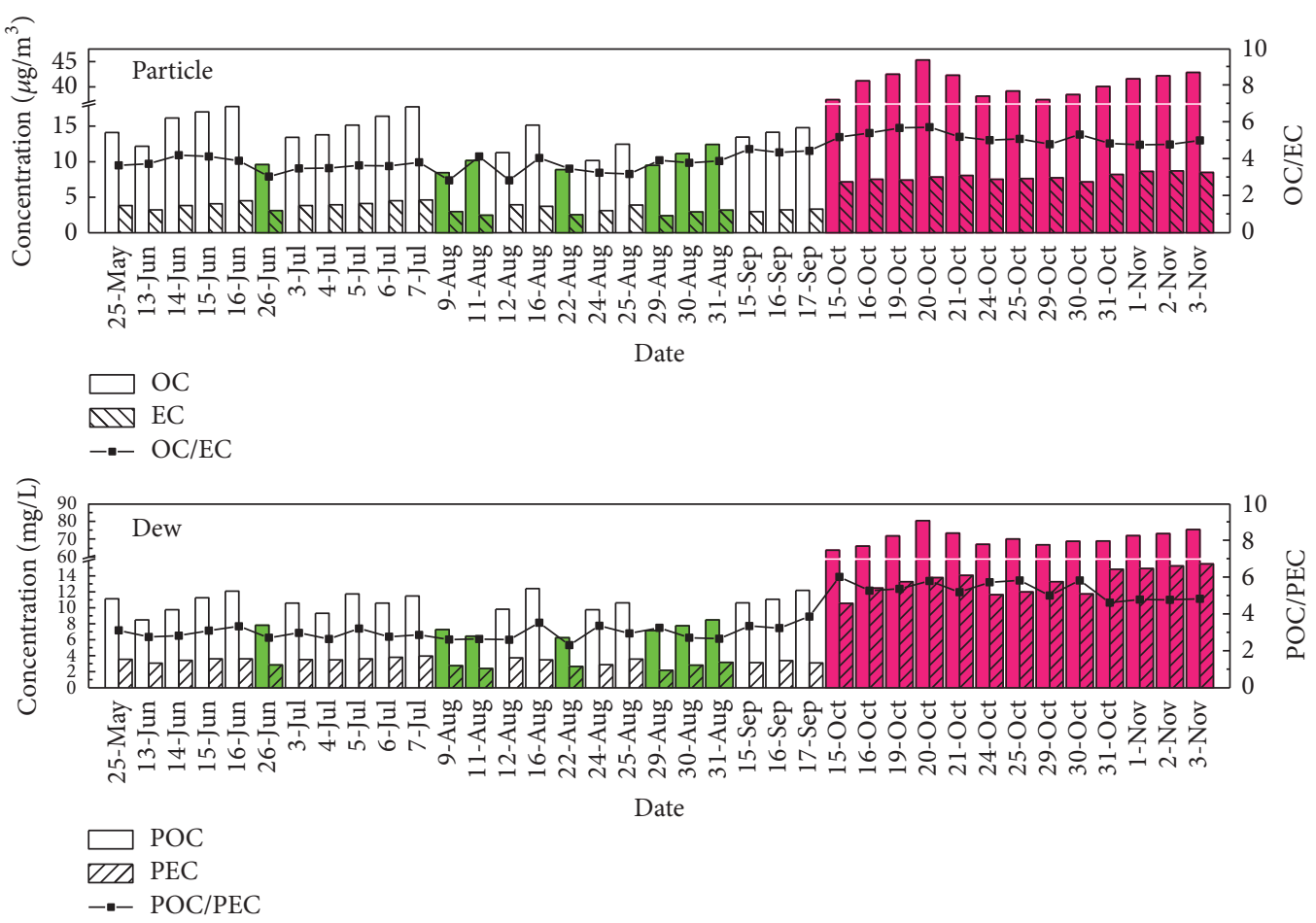

FIGURE 3: Ionic concentrations of organic carbon (OC) and elemental carbon (EC) of air particles, as well as particulate organic carbon (POC) and particulate elemental carbon (PEC) of dew during normal (white), foggy (green), and hazy (red) conditions in Changchun, China.

particles were consistent (Figure 3), suggesting that analysis of POC and PEC in dew could be used to identify the presence of SOC.

It is noted not only that OC is emitted from coal combustion, vehicle exhausts, and biomass burning, but also that it accumulates rapidly on fine particulate matter via photochemical reactions. Under low wind speeds and high atmospheric pressure, stagnation contributes to the accumulation of OC in haze as pollutants accumulate and form secondary aerosols.

\section{Conclusions}

Concentrations and compositions of dew and airborne particles in the near surface are closely related. The particle size distributions in dew and airborne particles were concordant under variable weather conditions. Air quality changes were most pronounced in haze with mass concentrations of TSP, $\mathrm{PM}_{2.5}$, and $\mathrm{PM}_{10}$ of around 2.78-4.29 times the normal levels. Similarly, TDS, $\mathrm{PM}_{2.5}$, and $\mathrm{PM}_{10}$ values in dew declined $0.50-0.63$ times in fog, but they increased 1.60-2.54 times in haze compared with normal dew. Ion concentrations in dew and airborne particles also had synchronous patterns. Watersoluble ions from different sources were enhanced more in dew than in airborne particles. In particular, the concentrations of crustal ions $\left(\mathrm{Ca}^{2+}, \mathrm{Na}^{+}\right.$, and $\left.\mathrm{Mg}^{2+}\right)$ in haze were 1.87-5.05 times the normal particle levels and 3.26-3.69 times the normal dew levels, while concentrations of anthropogenic pollution species $\left(\mathrm{SO}_{4}{ }^{2-}, \mathrm{NO}_{3}{ }^{-}\right.$, and $\left.\mathrm{NH}_{4}{ }^{+}\right)$were $3.89-5.98$ times the normal particle levels and 4.78-7.99 times the normal dew levels. Similarly, the concentrations of indicator species $\left(\mathrm{F}^{-}, \mathrm{Cl}^{-}\right.$, and $\left.\mathrm{K}^{+}\right)$of coal and biomass burning were 2.27-6.05 times the normal particle levels and 3.93-8.96 times the normal dew levels. With deterioration of air quality, the capability of dew to remove pollutants was decreased. The $\mathrm{PM}_{2.5}$ removal rates were $21.5 \%, 15.2 \%$, and $13.7 \%$ in normal, foggy, and hazy conditions, respectively. It appears that condensation processes reduce pollutant concentrations of gases and particulates in the near-surface atmosphere. Dew is helpful for the settlement of atmospheric particulates, and its rate of removal of coarse particulates is better than for fine material. The TSP removal rates were $28.2 \%, 13.7 \%$, and $18.5 \%$ in normal, foggy, and hazy weather. The changes in POC and PEC of dew and of OC and EC of airborne particles were consistent; therefore, analyzing the POC and PEC of dew could be used to identify SOC in the atmosphere. Dew composition can also be used to determine pollutant sources. Clearly, dew purifies urban air, and during hazy weather in particular, when air quality deteriorates dramatically, dew reduces local atmospheric pollution.

\section{Conflicts of Interest}

The authors declare that they have no conflicts of interest.

\section{Acknowledgments}

The authors gratefully acknowledge funding support from the National Natural Science Foundation of China (41401229), Science and Technology Program of Jilin 
Province (201705200827JH), and Foundation of Education Bureau of Jilin Province (2016161). The authors are indebted to the senior members of their team for their critical reading, kind remarks, and relevant suggestions. They also thank Professor Zhu who worked at the Northeast Institute of Geography and Agroecology, Chinese Academy of Sciences, for her linguistic assistance during the preparation of this manuscript.

\section{References}

[1] G. Gałek, M. Sobik, M. Błaś, Z. Polkowska, K. CichałaKamrowska, and K. Wałaszek, "Dew and hoarfrost frequency, formation efficiency and chemistry in Wroclaw, Poland," Atmospheric Research, vol. 151, pp. 120-129, 2015.

[2] D. Meunier and D. Beysens, "Dew, fog, drizzle and rain water in Baku (Azerbaijan)," Atmospheric Research, vol. 178-179, pp. 65-72, 2016.

[3] Z. Polkowska, M. Błaś, K. Klimaszewska, M. Sobik, S. Małk, and J. Namieśnik, "Chemical characterization of dew water collected in different geographic regions of Poland," Sensors, vol. 8, no. 6, pp. 4006-4032, 2008.

[4] M. A. Rubio, E. Lissi, N. Herrera, V. Pérez, and N. Fuentes, "Phenol and nitrophenols in the air and dew waters of Santiago de Chile," Chemosphere, vol. 86, no. 10, pp. 1035-1039, 2012.

[5] G. Gałek, M. Sobik, M. Błaś, Ż. Polkowska, and K. CichałaKamrowska, "Urban dew formation efficiency and chemistry in Poland," Atmospheric Pollution Research, vol. 7, no. 1, pp. 18-24, 2016.

[6] P. Muskała, M. Sobik, M. Błaś, Z. Polkowska, and A. Bokwa, "Pollutant deposition via dew in urban and rural environment, Cracow, Poland," Atmospheric Research, vol. 151, pp. 110-119, 2015.

[7] Y. Xu, H. Zhu, J. Tang, and Y. Lin, "Chemical compositions of dew and scavenging of particles in changchun, china," Advances in Meteorology, vol. 2015, Article ID 104048, 2015.

[8] I. Lekouch, M. Muselli, B. Kabbachi, J. Ouazzani, I. Melnytchouk-Milimouk, and D. Beysens, "Dew, fog, and rain as supplementary sources of water in south-western Morocco," Energy, vol. 36, no. 4, pp. 2257-2265, 2011.

[9] M. Q. Huo, Q. Sun, P. Xie et al., "Relationship between atmospheric particles and rain water chemistry character," Environmental Science, vol. 30, no. 11, pp. 3159-3166, 2009.

[10] M. Hu, J. Zhang, and Z. J. Wu, "Chemical compositions of precipitation and scavenging of particles in Beijing," Science China Chemistry, vol. 48, no. 3, pp. 265-272, 2005.

[11] M. Chiwa, N. Oshiro, T. Miyake et al., "Dry deposition washoff and dew on the surfaces of pine foliage on the urban- and mountain-facing sides of Mt. Gokurakuji, western Japan," Atmospheric Environment, vol. 37, no. 3, pp. 327-337, 2003.

[12] A.-T. J. Ernesto and F.-P. J. Jasson, "Winter dew harvest in Mexico City," Atmosphere, vol. 7, no. 1, article no. 2, 2016.

[13] G. Tang, P. Zhao, Y. Wang et al., "Corrigendum to 'Mortality and air pollution in Beijing: The long-term relationship' [Atmospheric Environment 150C (2017) 238-243]," Atmospheric Environment, vol. 157, p. 167, 2017.

[14] B. Chen, S. Wang, W. Yang, R. Yan, X. Chen, and Q. Zhang, "Characteristics and origins of a typical heavy haze episode in Baotou, China: implications for the spatial distribution of industrial sources," Journal of Zhejiang University-SCIENCE A, vol. 18, no. 2, pp. 151-162, 2017.
[15] X. Y. Zhang, Y. Q. Wang, and T. Niu, "Atmospheric aerosol compositions in China: spatial/temporal variability, chemical signature, regional haze distribution and comparisons with global aerosols," Atmospheric Chemistry and Physics, vol. 12, no. 2, pp. 779-799, 2012.

[16] J. Gao, A. Woodward, S. Vardoulakis et al., "Haze, public health and mitigation measures in China: A review of the current evidence for further policy response," Science of The Total Environment, vol. 578, pp. 148-157, 2017.

[17] Y. Pan, Y. Wang, J. Zhang et al., "Redefining the importance of nitrate during haze pollution to help optimize an emission control strategy," Atmospheric Environment, vol. 141, pp. 197202, 2016.

[18] Y. Xu, H. Zhu, and J. Tang, "The effects of haze on dew quality in the urban ecosystem of Changchun, Jilin Province, China," Environmental Monitoring and Assessment, vol. 188, no. 2, article no. 124, pp. 1-10, 2016.

[19] A. Lakhani, R. S. Parmar, and S. Prakash, "Chemical composition of dew resulting from radiative cooling at a semi-arid site in Agra, India," Pure and Applied Geophysics, vol. 169, no. 5-6, pp. 859-871, 2012.

[20] M. A. Rubio, E. Lissi, and G. Villena, "Factors determining the concentration of nitrite in dew from Santiago, Chile," Atmospheric Environment, vol. 42, no. 33, pp. 7651-7656, 2008.

[21] Y. L. Sun, G. S. Zhuang, A. H. Tang, Y. Wang, and Z. S. An, "Chemical characteristics of $\mathrm{PM}_{2.5}$ and $\mathrm{PM}_{10}$ in haze-fog episodes in Beijing," Environmental Science and Technology, vol. 40, no. 10, pp. 3148-3155, 2006.

[22] Y. Wang, G. Zhuang, Y. Sun, and Z. An, "The variation of characteristics and formation mechanisms of aerosols in dust, haze, and clear days in Beijing," Atmospheric Environment, vol. 40, no. 34, pp. 6579-6591, 2006.

[23] J. H. Tan, J. C. Duan, and K. B. He, "Chemical characteristics of $\mathrm{PM}_{2.5}$ during a typical haze episode in Guangzhou," Journal of Environmental Sciences, vol. 21, no. 6, pp. 774-781, 2009.

[24] M. Zheng, L. G. Salmon, J. J. Schauer et al., "Seasonal trends in PM2.5 source contributions in Beijing, China," Atmospheric Environment, vol. 39, no. 22, pp. 3967-3976, 2005.

[25] D. K. Deshmukh, M. K. Deb, Y. Suzuki, and G. N. Kouvarakis, "Water-soluble ionic composition of $\mathrm{PM}_{2.5-10}$ and $\mathrm{PM}_{2.5}$ aerosols in the lower troposphere of an industrial city Raipur, the eastern central India," Air Quality, Atmosphere and Health, vol. 6, no. 1, pp. 95-110, 2013.

[26] S. L. Tian, Y. P. Pan, and Y. S. Wang, "Size-resolved source apportionment of particulate matter in urban Beijing during haze and non-haze episodes," Atmospheric Chemistry and Physics, vol. 16, no. 1, pp. 1-19, 2016.

[27] A. Ianniello, F. Spataro, G. Esposito et al., "Occurrence of gas phase ammonia in the area of Beijing (China)," Atmospheric Chemistry and Physics, vol. 10, no. 19, pp. 9487-9503, 2010.

[28] H. Dong, L. Zeng, M. Hu et al., "Technical Note: The application of an improved gas and aerosol collector for ambient air pollutants in China," Atmospheric Chemistry and Physics Discussions, vol. 12, no. 3, pp. 7753-7791, 2012.

[29] G. R. Wentworth, J. G. Murphy, K. B. Benedict, E. J. Bangs, and J. L. Collett, "The role of dew as a night-time reservoir and morning source for atmospheric ammonia," Atmospheric Chemistry and Physics, vol. 16, no. 11, pp. 7435-7449, 2016. 

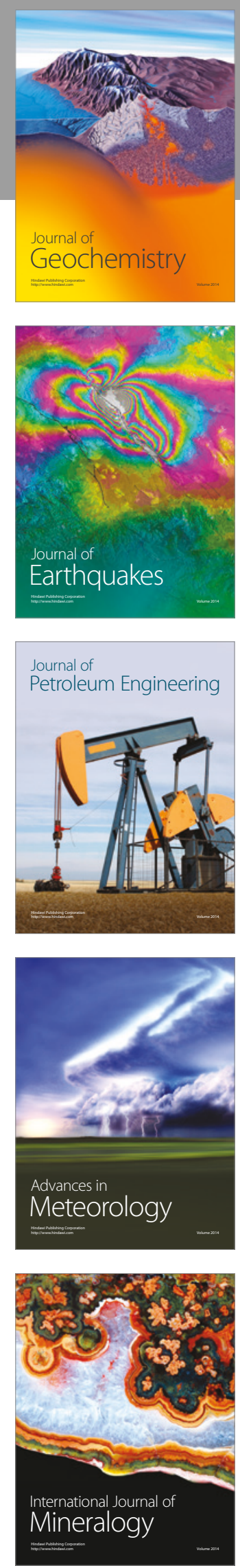
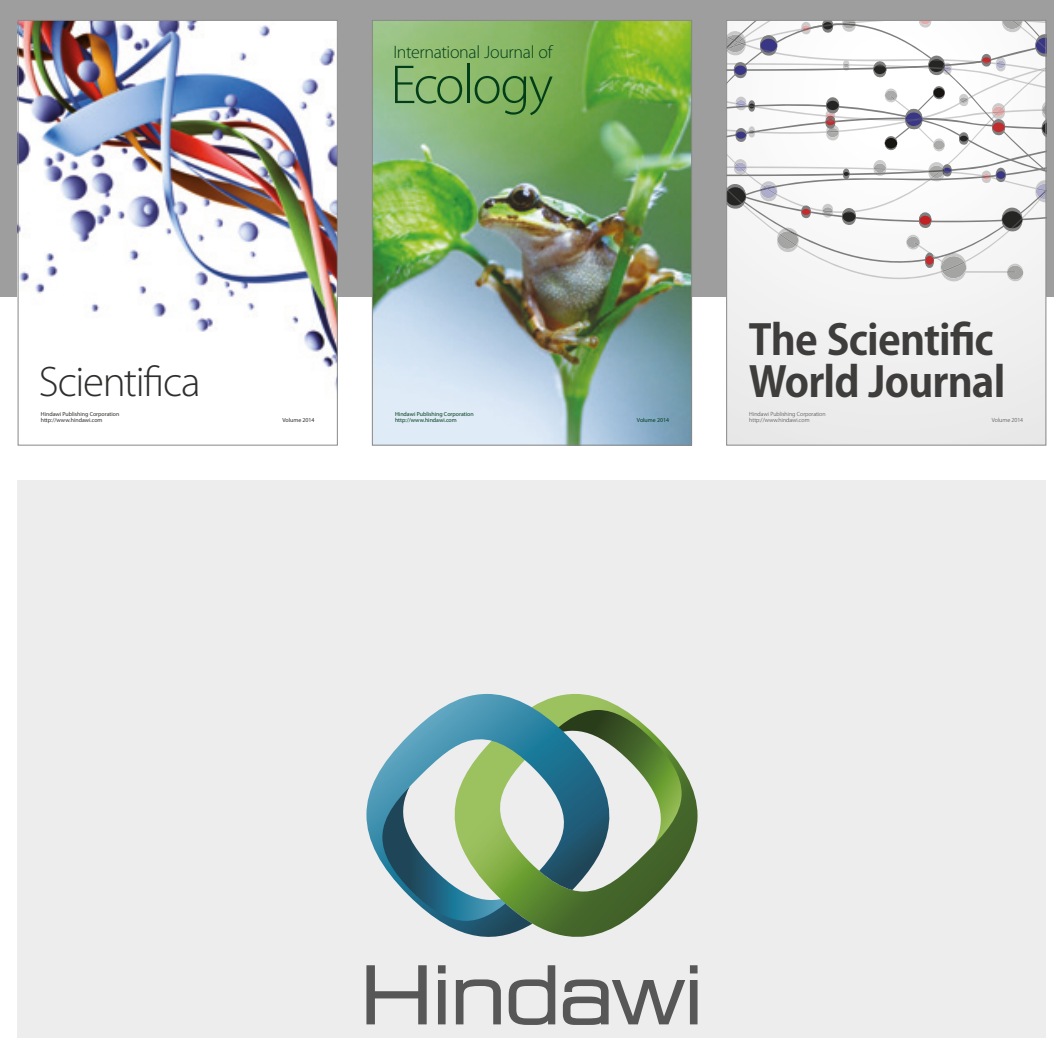

Submit your manuscripts at

https://www.hindawi.com
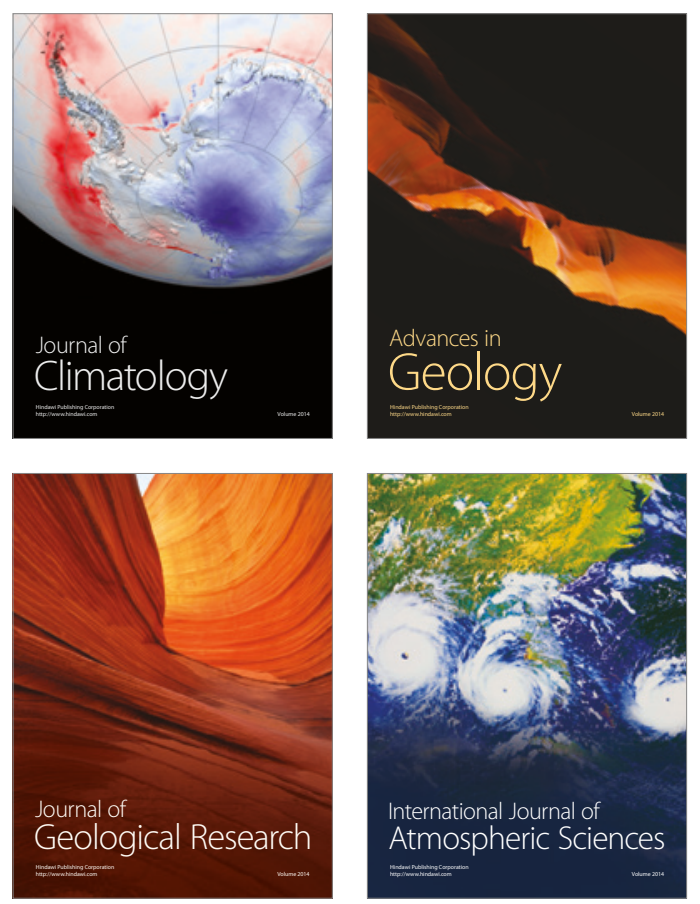

The Scientific

World Journal
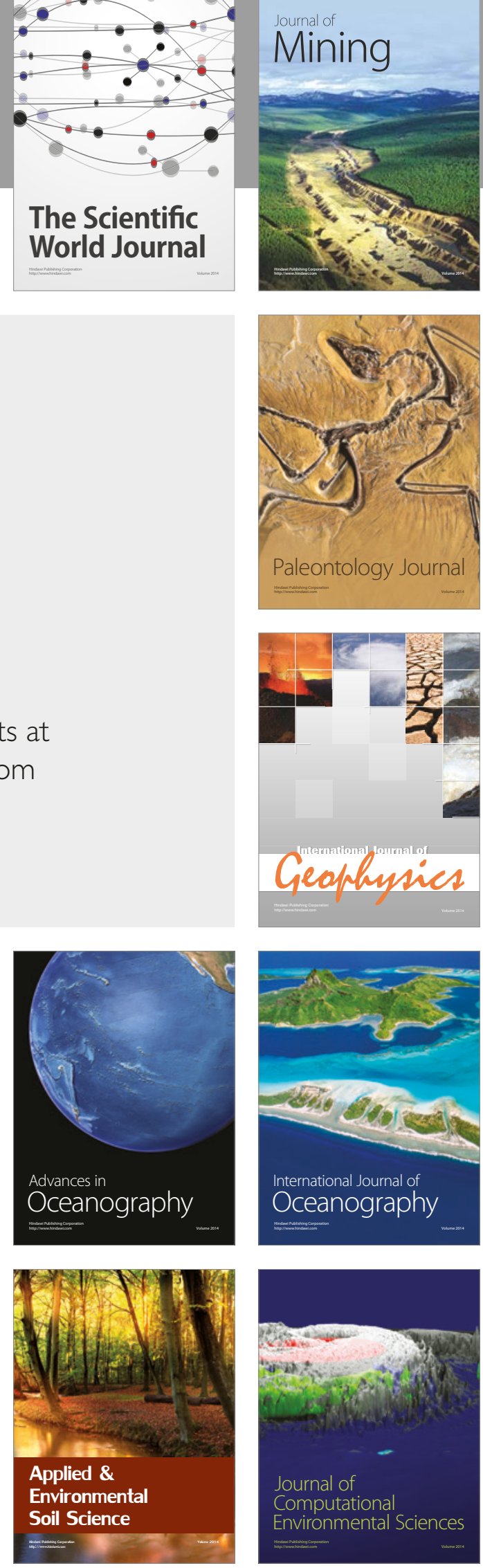